\title{
Editorial
}

\section{Conceptions of medical humanities}

David Greaves, Martyn Evans Centre for Philosophy and Health Care, University of Wales

In the first issue of Medical Humanities we raised the question of the relationship between medical ethics (or bioethics) and medical humanities, and this question is presently receiving considerable attention. Last September it occupied two important meetings, one being a workshop at the International Association of Bioethics World Congress in London, and the other being a joint seminar involving Oxford University and the Hastings Center, the premier US bioethics institution. In North America as a whole, ethics and humanities have already begun converging, with scholarly associations joining forces and some university departments combining ethics and humanities in their titles.

Here it is significant that this journal has been launched as a special edition of the fournal of Medical Ethics, giving the impression perhaps that humanities is either a subsidiary of, or an accessory to, ethics. However, this simply reflects the sequence in which the subjects have developed historically, and the relation between them could be seen in other ways. One view envisages medical ethics as just one among a number of subdisciplines, which jointly constitute a wider inquiry, medical humanities. Another sees medical humanities as a larger perspective through which ethical issues emerge as part of an interdisciplinary approach to medical practice and theory. On this view, moral issues are recognised as furnishing one of many pervasive elements of the whole of medical and health care. A third approach is to regard the medical humanities as a sustained exploration of both theory of knowledge (epistemology) and value-inquiry, as these are embodied in clinical medicine. Ethical values are central to, but do not exhaust, value-inquiry in medicine. Indeed, one could argue that a richer understanding of the widest range of human values and goals - as these feature in the lives and perspectives of patients and practitioners alike- is a crucial part of taking moral concerns seriously.

Readers of both this journal and its "parent" may take different views on this question, and we hope to prompt your contributions to lively correspondence and debate in future issues.

In the present issue we continue the general task of establishing some characteristic enquiries within the integrated conception of the medical humanities - that conception under which humanities perspectives are taken to lie alongside the natural sciences at the core of our understanding of medicine's nature and goals.
Thus in addition to our regular columns, this issue carries six substantial papers from different disciplinary and geographical sources.

First, physician Leopoldo Acuna from La Plata University, Argentina relates how medical humanities was established in Argentina more than two decades ago, drawing on European influences but strikingly predating the arrival of medical humanities as a self conscious area of study in Europe.

This is followed by two papers in a crucial area for the medical humanities' credibility, namely the evaluation of evidence for the health-related impact of the arts and humanities. Architect Peter Scher and Arts for Health Director Peter Senior present the first published report of their study of the impact of arts interventions in a hospital environment (and, incidentally, this journal's first "empirical" paper). Writer Mark Robinson continues this theme in the context of "therapeutic" expressive writing - asking whether, beyond simply writing at all, it matters therapeutically whether the writing is done well.

Then Strasbourg-based general practitioner Iain Bamforth offers what is both a discussion and an instance of expressive writing, in his elegant study of the ambiguity between suffering, purpose, and literature in both the illness and the art of Franz Kafka - and in the medical treatment Kafka received and described.

Our last two papers, in both origin and subject matter, reflect the special role of narrative in constructing meaning; significantly both come from practitioners in psychiatric services. Psychiatrist Jeremy Holmes examines psychotherapy as the quintessential "narrative" clinical specialism, and as a vivid example of the need for narrative to be integrated with evidence-based medicine, before the clinical skills associated with narrative are submerged by the pressure of the evidence-base paradigm. Finally, psychiatric nursing professor Phil Barker gives us an intriguing reflection on the all-pervading role of metaphor in our lives and self conceptions, and thence in the way we try to give meaning to our experiences of suffering and death-recognising the resources for metaphor which the liberal arts offer us.

David Greaves and Martyn Evans are Senior Lecturers at the Centre for Philosophy and Health Care, University of Wales Swansea, Swansea SA2 8PP. 